\title{
Recurrent hamartoma at the trocar incision site after video-assisted thoracic surgical resection
}

\author{
Corinna Ludwig, MD, B. Passlick, MD, and Erich Stoelben, MD, Freiburg, Germany
}

$\mathrm{T}$ he most common benign tumor of the lung is the hamartoma representing $77 \%{ }^{1}$ Hamartomas represent $4 \%$ to $8 \%$ of all solitary pulmonary nodules, ${ }^{2}$ which present themselves as well-circumscribed, asymptomatic coin lesions within the pulmonary parenchyma. ${ }^{3}$ Usually they are chondromatous hamartomas consisting of cartilage and are regarded as benign neoplasms derived from the peribronchial mesenchymal tissue. Symptoms such as cough, hemoptysis, or pulmonary infections arise only when the location is endobronchial, which is rare $(10 \%)$. There is an overall incidental finding in approximately $0.25 \%$ of autopsies, and hamartomas are found more frequently in men than in women (2:1). ${ }^{3}$ Multiple hamartomas are rare and do not include cartilage but pulmonary muscular or endothelial tissue and are therefore called hemangioleiomyomatous and fibroleiomyomatous hamartomas.

In the case of a solitary lesion it is necessary to exclude malignancy. Percutaneous, transthoracic computed tomographyguided needle aspiration biopsy yields diagnosis in $85 \%$ of solitary pulmonary coin lesions. The risk of pneumothorax is high, ranging from $20 \%$ to $24 \%{ }^{4}$ Video-assisted thoracic surgical (VATS) resection offers a safe and $100 \%$ sure method to obtain a diagnosis with little discomfort for the patient. Most authors recommend enucleation or tissue-sparing resection of the chondromatous hamartoma. ${ }^{4,5}$ Recurrence after excision is practically unknown.

\section{Clinical Summary}

We report the case of a 62-year-old patient with a history of a pulmonary chondromatous hamartoma in segment 3 of the left lung. In 1999, a solitary pulmonary nodule, $2 \mathrm{~cm}$ in diameter, was discovered on a chest $\mathrm{x}$-ray film, which was performed to exclude pneumonia after a viral infection. Bronchoscopy was not diagnostic, and the patient was referred to our center. A VATS resection was performed using three $10-\mathrm{mm}$ ports. The nodule was located by endoscopic palpation and enucleated. The hamartoma was then extracted by using an Endopouch (Ethicon Endo-Surgery, Inc, Cincinnati, Ohio).

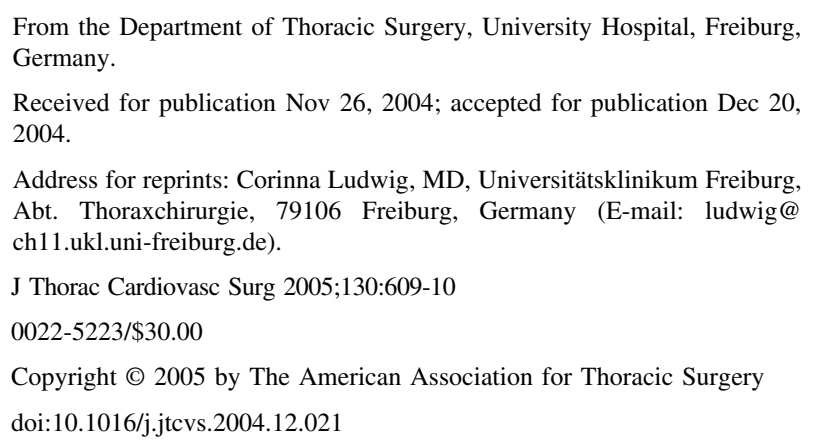

Three years later (2002) a routine examination of the chest showed a partial obstructive atelectasis of the right lower lobe. Bronchoscopy revealed an exophytic tumor growing out of segment 8. Histopathologic examination confirmed the suspicion of a squamous cell lung cancer. Preoperative examinations showed no evidence of distant metastatic disease, and a sleeve resection of the right lower lobe was performed with a reanastomosis of the middle lobe. Histopathologic staging was $\mathrm{pT} 2 \mathrm{pN} 1 \mathrm{cM} 0$, requiring no further treatment.

In February 2004, again during a routine computed tomography, a left lateral nodular chest wall lesion was detected that was suspicious of a pleural metastasis (Figure 1). A second VATS procedure on the left side was performed, and there was no evidence of pleura carcinosis. However, at the site of the previous port incision in the fifth intercostal space a tumor of $2 \mathrm{~cm}$ in diameter located in the parietal pleura was found (Figure 2). Endoscopic resection of the parietal pleura and surrounding intercostal tissue with a 2-cm security margin was possible. The lesion was once again extracted with an Endopouch. Histologic examination revealed a benign chondroid tumor; because of the localization, a pleural recidivation of the chondromatous hamartoma was assumed.

\section{Discussion}

Even if there is little or no risk of malignant transformation of chondromatous hamartomas, surgical removal is the therapy of choice to be certain of the dignity. Enucleation of the subpleural

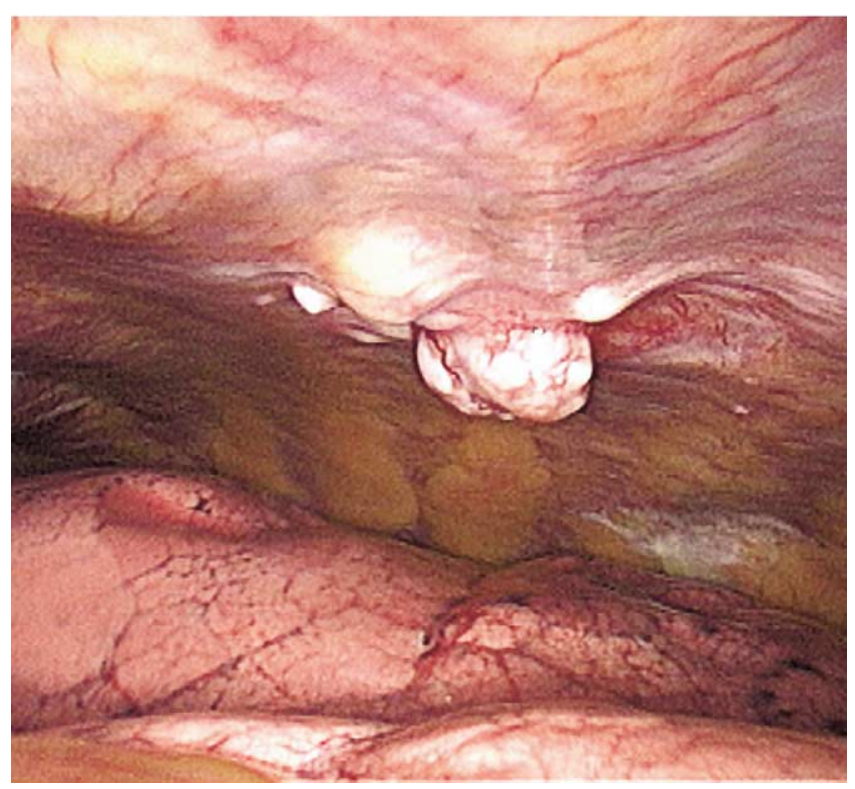

Figure 1. Routine computed tomography with left pleural lesion. 


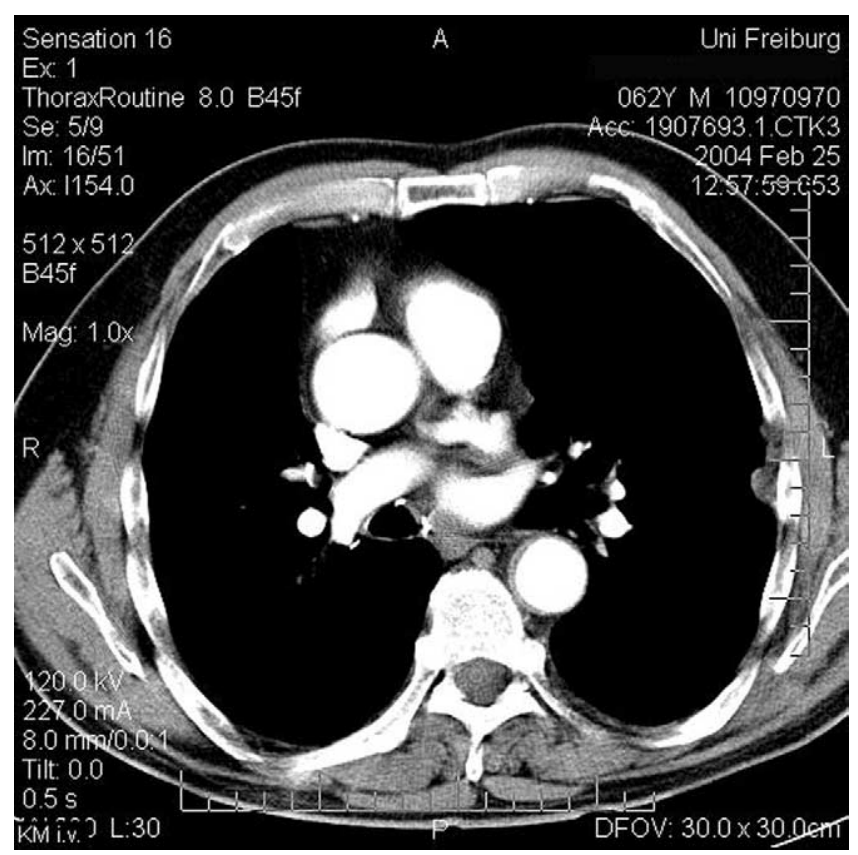

Figure 2. Intraoperative picture of the recurrent pleural chondromatous hamartoma. lesion seems to be a frequently used method. ${ }^{1}$ It is assumed that once the lesion is removed it does not reoccur. ${ }^{3,5}$ In the presented case we have evidence to the contrary. Even though the lesion was removed with an Endopouch, there was obviously a contamination of the pleural space. This might be because of residual material of the hamartoma within the lung tissue or manipulation with the instruments. Parenchyma-sparing wedge resection of is probably the better method to resect a pulmonary hamartoma to avoid chest wall contamination.

\section{References}

1. Arrigoni MG, Woolner LB, Bernatz PE, et al. Benign tumors of the lung. A ten-year surgical experience. J Thorac Cardiovasc Surg. 1970; 60:589-99.

2. Khouri NF, Meziane MA, Zerhouni EA, et al. The solitary pulmonary nodule. Assessment, diagnosis, and management. Chest. 1987; 91:128-33.

3. Gjevre JA, Myers JL, Prakash UB. Pulmonary hamartomas. Mayo Clin Proc. 1996;71:14-20.

4. Hamper UM, Khouri NF, Stitik FP, Siegelman SS. Pulmonary hamartoma: diagnosis by transthoracic needle-aspiration biopsy. Radiology. 1985; 155:15-8.

5. Hansen CP, Holtveg H, Francis D, et al. Pulmonary hamartoma. J Thorac Cardiovasc Surg. 1992;104:674-8.

\title{
Large cell carcinoma arising in bronchogenic cyst
}

\author{
Marko Jakopovic, MD, ${ }^{a}$ Zoran Slobodnjak, MD, PhD, ${ }^{a}$ Simun Krizanac, MD, PhD, ${ }^{\text {b }}$ and
}

Miroslav Samarzija, MD, PhD, ${ }^{\text {a }}$ Zagreb, Croatia

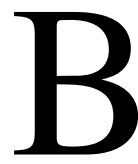

ronchogenic cysts are thought to originate from abnormal budding of the ventral foregut. The majority are located in the mediastinum, usually in the subcarinal or paratracheal region. Approximately 15\% are reported to arise in the lung. Other locations, such as the pleura, pericardium, or diaphragm, are rare. Bronchogenic cysts are lined by

From the University Hospital for Lung Diseases "Jordanovac,"a and De-

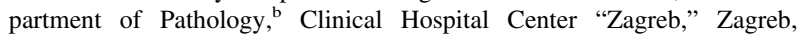
Croatia.

Received for publication Nov 19, 2004; accepted for publication Dec 20, 2004.

Address for reprints: Marko Jakopovic, University Hospital for Lung Diseases "Jordanovac," Jordanovac 104, 10000 Zagreb, Croatia (E-mail: mjakopovic2001@yahoo.com).

J Thorac Cardiovasc Surg 2005;130:610-2

$0022-5223 / \$ 30.00$

Copyright $\odot 2005$ by The American Association for Thoracic Surgery doi:10.1016/j.jtcvs.2004.12.022 pseudostratified, columnar, ciliated (respiratory) epithelium and may contain serous fluid, mucus, blood, or purulent material. These cysts usually occur in adults but may occur in any age group. Patients usually remain asymptomatic, even though infection or bleeding produces symptoms in up to two thirds of cases. Symptoms associated with these cysts are much more common in children, in whom large cysts may compress the airways with resultant atelectasis, pneumonia, or air trapping.

We report a rare case of carcinoma arising in a bronchogenic cyst.

\section{Clinical Summary}

A 40-year-old woman with no medical history was admitted to the hospital because of radiographically proven complete pneumothorax of the right lung. Two weeks before the admission, the patient felt sudden pain in the right thorax spreading to the right shoulder with dyspnea associated with minimal physical activity. The patient's condition was growing worse with progressive dyspnea, and she felt a lack of air even during rest. She reported to the emergency department where a chest radiograph was performed, show- 